\title{
Frequency of somatic complains among patients with mental illness Anum Haider ${ }^{1}$ \& Usama Asad ${ }^{2}$
}

\author{
${ }^{1}$ Dow Medical college, Dow University of Health Sciences, Karachi \\ ${ }^{2}$ Sindh Medical University, Karachi. \\ Corresponding Author Email: anum.haider@duhs.edu.pk \\ Received 10/05/2018; Accepted 20/09/2018; Published 10/10/2018
}

\section{Abstract}

Background: It is established that physical and mental disorders share common risk factors, among those the unhealthy lifestyle is most common. In order to achieve complete health, it is crucial to monitor both physical and mental health. Mental health problem is the most deserving area to work with because physical health issues are often neglected or mismanaged. This study intends to unveil the frequency of somatic (physical) health complains among patients with mental illness. Methodology: In this cross-sectional study total 85 patients were enrolled from Psychiatry Out Patient Department, Civil Hospital Karachi, during $16^{\text {th }}$ October to $13^{\text {th }}$ November 2015. Patients were asked about the demographic details and existing somatic complaints from the pre-formulated questionnaire while data was analyzed on SPSS. Results: $32.9 \%$ of the subjects were diagnosed with particular medical comorbidity. However, among undiagnosed somatic (physical) complains; endocrinological complaints were more frequent i.e. $16.7 \%$ followed by $14.2 \%$ Gastrointestinal (GIT) and $13.68 \%$ Central Nervous System (CNS). Conclusion: The current study supported the fact that there is a high frequency of somatic complaints in patients with mental illness. Physical monitoring is crucial for early identification and better prognosis.

\section{Keywords}

Somatic Complains, Mental Illness, Unhealthy Life Style, Physical Monitoring.

\section{Introduction}

The ability to perform well at work and to fulfill the responsibilities depends on the physical and mental well-being of a person. If health compromises in either way it may hamper the overall functioning of an individual (Alonso et al., 2014). The physical and mental problems are often found to be interlinked but only a few studies have explained the basis of such linkage. Multisystem involvement due to the dysregulated inflammatory background is identified as the underpinning factor for cardiovascular and bipolar disorders (Leboyer et al., 2012). The main explanation of centrally driven pain conditions like Irritable bowel syndromeIBS, fibromyalgia, and interstitial nephritis can be considered as other possible mechanisms. These disorders mimic mood disorders and respond well to CNSneuromodulatory agents like Serotonin Norepinephrine Reuptake Inhibitor-SNRI and anticonvulsants (Phillips, 2011). Inflammation is a state shared by both physical and psychiatric disorders which play a bidirectional causational role, disrupting the neuroregulatory systems (serotonergic, dopaminergic, neuropeptide Y) and Hypothalamic-Pituitary-Adrenal Axis (HPA) (Nousin, 2013).

Broadly if we classify the possible risk factors to activate the inflammatory mechanism, it might go into three dimensions; biological that includes obesity, sedentary lifestyle, smoking and any disability, psychological including chronic stressors, adverse life events, abuse, neglect) and social includes poverty, 
neighborhood, social support, isolation, household dysfunctions. These factors act in an integrated manner to disrupt the HPAaxis and neural circuitry resulting in the manifestation of various physical and psychiatric problems (Druss, 2011). The unhealthy lifestyle such as smoking, alcohol, and substance abuse, lack of physical activity, poor eating habits, suboptimal hygiene and disturbed sleep pattern) is identified as modifiable risk factor for many physical problems making the population more vulnerable (Scott, 2011 \& Druss, 2011).

Mental illness itself, is more likely to be associated with disability and physical problems such as obesity, metabolic syndrome, Diabetes Mellitus-DM, cardiovascular and respiratory issues are almost twice more common in patients with severe mental illness than that of general population and it may also increase the mortality risk up to five times (Scott et al., $2009 \&$ Hayward, 1995). The association of mental illness with other somatic complains and medical comorbidities may play a synergistic role by adding on the burden. It not only impairs quality of life but also compromises life expectancy to such an extent that almost 30 years of life may be lost in this population (Scott et al., 2009 \& Hayward, 1995).

Beside Psychotropic use such as antipsychotics which have established role in causing obesity and metabolic syndrome, there is a complex interplay of neurobiological (genetics, leptin sensitivity, HPA axis), Psychological (Negative emotions, stress proneness, Type A Personality, hostility) and social factors (low social support, poverty, alcohol, substance use) in the presentation of physical health problems (Taylor et al., 2012 \& Smith, 2011).

Cardiovascular problems are among the most commonly identified physical comorbidities in patients with mental illness while the possible underlying phenomenon studied is perseverative cognition especially those with mood and anxiety disorders which may delay physiological recovery from acute stress but also increases the risk for cardiovascular damage (Larsen, 2009). Despite the high rate of physical comorbidity, it's going to be unattended and mislabeled as psychosomatic or functional at a significantly high rate and ultimately worsening the psychological stability, treatment adherence, life expectancy and quality of life (Hert, 2011 \& Gray, 2012).

Studies have reported that psychiatrists were found to be more frequent in overlooking medical problems in patients with medical illness than that of physicians, however, the physical comorbidity rate was actually estimated to be $43 \%$ in those patients (Koryani, 1979). Patients with mental illness, the most hampering factor identified in seeking help is a stigma (Mercer et al., 2012). This delay in identification and management of physical health problems in mentally ill patients makes premature mortality highly prevalent. Even in high-income countries, the male population with mental illness die around 20 years while females 15 years earlier than the general population (Thornicroft, 2011 \& Lawrence, 2013).

Besides, presenting as a comorbidity, physical problems may also manifest psychiatric problems and may be misdiagnosed as a psychiatric illness. Hall et al in his study reviewed the previously diagnosed psychiatric cases by a combination of physical, psychiatric and neurological examinations followed at labs. He came up with the medical diagnosis in around $46 \%$ of cases (Hall et al., 1980). The ultimate question arises in mind, how such an important presentation can be overlooked by health professionals? The research has proposed the possible answer like lack of screening and assessment of 
physical health aspects. Other possibilities are variable presentations due to patient and carer's race and ethnic characteristics, the deficits in a system including lack of resources, poverty, inaccessible health services (Hert et al., 2011 \& Hitchen, 2011). At a system level, actions are not easy to recognize but at the individual level, simple and basic care can improve the suboptimal medical care. Psychiatrists can play a crucial role by expanding the clinical paradigm including physical monitoring and adherence to treatment guidelines. Educating patients to control suboptimal lifestyle factors and promoting healthy health behaviors (diet, exercise, smoking cessation) may have a remarkable advantage over physical health outcomes (Hert et al., 2011 \& Hitchen, 2011).

Considering the importance of the subject and lack of research in this regard especially in the third world countries like Pakistan, this study aimed to determine the frequency of somatic complains among patients with mental illness so that clear picture may come upon the surface to better raise the consideration on an important area.

As it has a bidirectional impact, physical and mental disorders may synergistically affect not only an individual's quality of life but at the gross level adversely affects the economy. At the individual level it hampers the productivity and impairs the economy by high utilization of resources. There is a high need to narrate the future health plan accordingly, to better cope with the discussed issue and to get the better health outcome and economy consequently.

\section{Methodology}

A cross-sectional study was conducted in Psychiatry Out Patient Department, Civil Hospital Karachi, thrice per week during $16^{\text {th }}$ October to $13^{\text {th }}$ November 2015. Convenience sampling technique was used and informed consent was obtained. Patients presented with the reliable informant and clearly defined somatic complains, agree to visit the site and diagnosed with mental illness from ICD-10 diagnostic criteria previously and proficient in speaking the Urdu language were included in the study. However, those who were unstable or unwilling were excluded. Total 85 patients were selected and interviewed via a semi-structured questionnaire. The questionnaire includes chief complaints of the major vital systems such as cardiovascular system (CVS), respiratory system, central nervous system (CNS), Gastrointestinal (GI), endocrine, dental, dermatological, genitourinary and locomotory system. The list of somatic complains was adapted from the local book of bedside techniques. Data was analyzed using SPSS version. 19.

Result

Among 85 patients, the mean age of presentation was $34.87 \pm 13.46$ years. Majority of the study participants were males 56(66\%) and married 42(49.4\%). About one third $28(32.9 \%)$ of the patients were observed with diagnosed medical comorbidity. Among these, Hypertension $(16.7 \%)$ was the most frequent followed by hepatitis, Tuberculosis (TB), Asthma, Diabetes mellitus (DM) and hyperlipidemia as shown in table 1 . 
Table 1: Demographic Characteristics

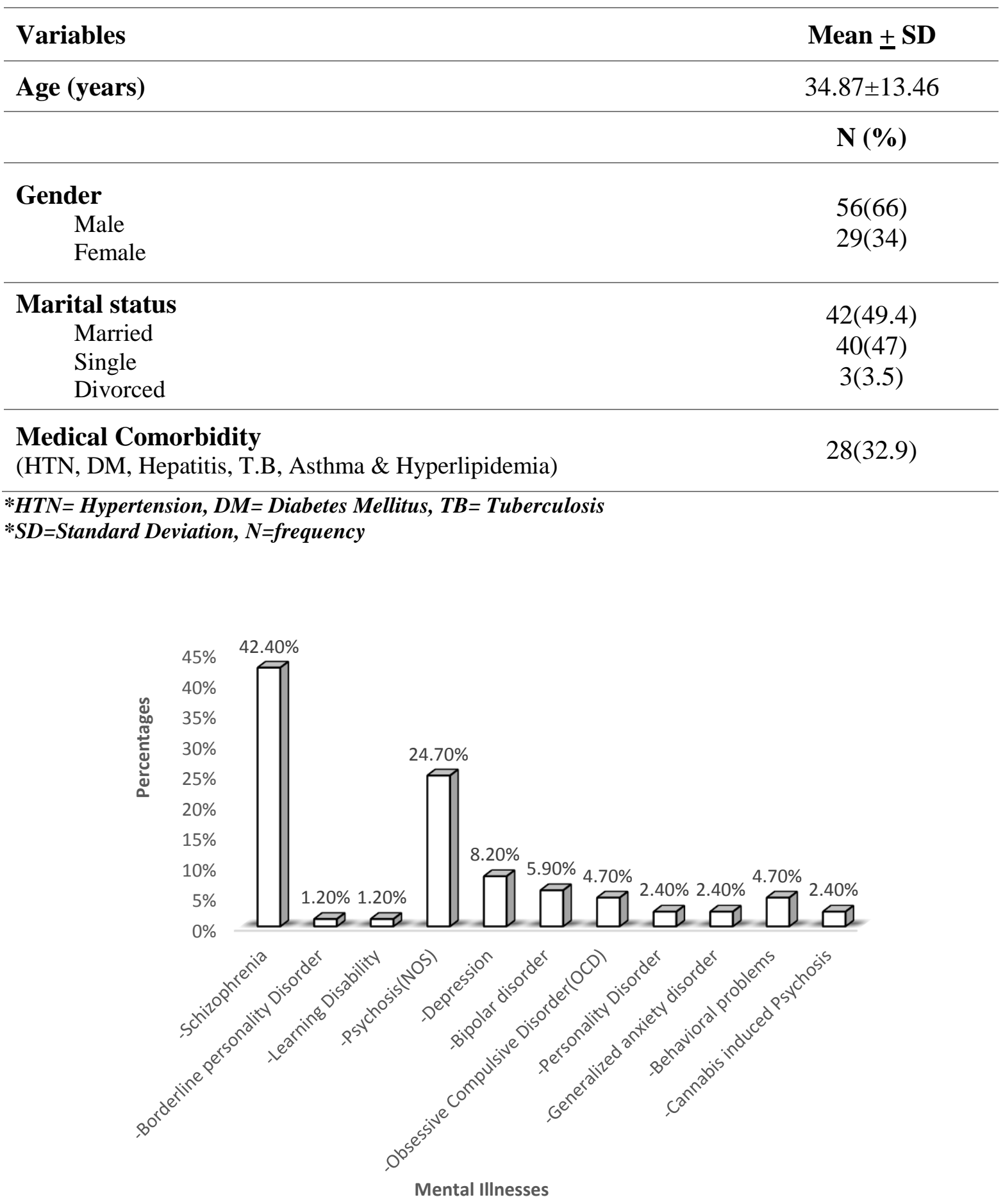

*NOS=Not Otherwise Specified

Figure 1: Frequency of psychiatric illness $(\mathbf{n}=\mathbf{8 5})$

In the studied sample, Schizophrenia was the more frequently found psychiatric diagnosis i.e. $42.4 \%$ followed by psychosis $24.7 \%$, depression $8.2 \%$ and bipolar disorder $5.9 \%$. 


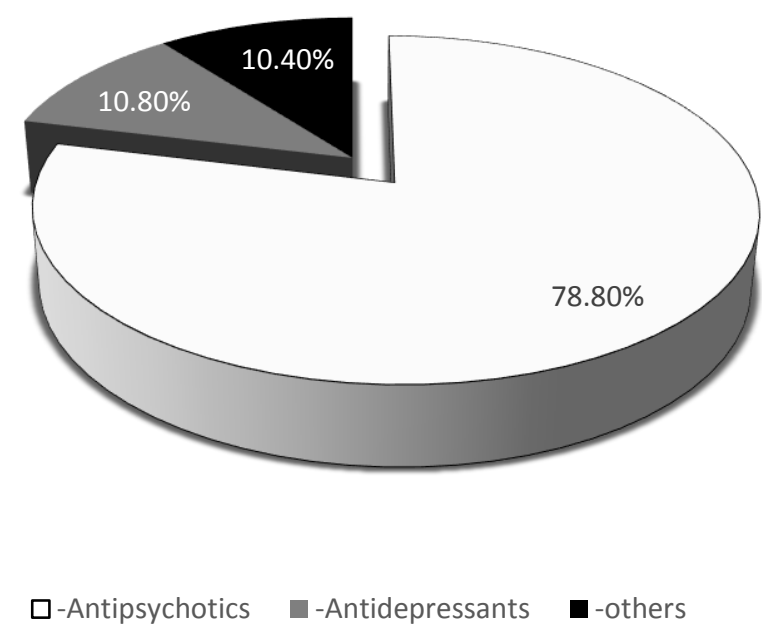

Figure 2: Frequency of Psychotropic Use

According to the results in figure 2, Antipsychotics use was also found to be pronounced (78.8\%) among the studied population.

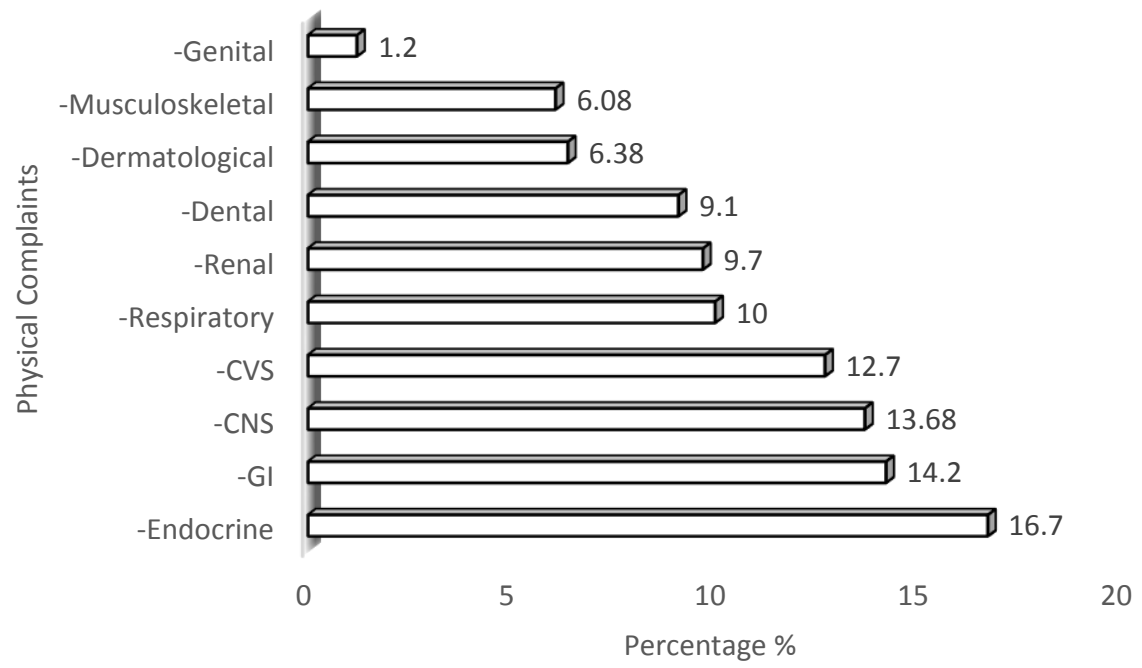

*CVS=Cardiovascular system; CNS= Central Nervous System; GI= Gastrointestinal Tract

Figure 3: Frequency of Physical Complaints in the vital organ systems

Among undiagnosed physical complains of the vital organ systems, Endocrinological complaints were found to be more frequent $16.7 \%$ followed by GI $14.2 \%$, CNS $13.68 \%$, CVS $12.7 \%$, Respiratory $10 \%$, Renal 9.7\%, Dental 9.1\%, dermatological $6.38 \%$, musculoskeletal $6.08 \%$ and genital $1.2 \%$.

While the most frequent Systemic complains among studied systems were; Palpitation(45\%), Breathing problems (37\%), Constipation (20\%), Increased frequency in micturition (50\%), Rash (60\%), Joint pain (80\%), Polydipsia (54.5\%), Xerostomia (85.5\%), unspecified genital complaints $(100 \%)$ and headache $(42 \%)$ as described in Table 2. 
Table 2: Distribution of physical complains in individual systems

\begin{tabular}{|c|c|c|}
\hline Physical Systems & Complaints & $\mathbf{N}(\%)$ \\
\hline Cardiovascular & $\begin{array}{c}\text { Palpitation } \\
\text { Chest pain } \\
\text { Syncope } \\
\text { Unspecified/mixed }\end{array}$ & $\begin{array}{c}5(45) \\
3(27) \\
2(19) \\
1(9)\end{array}$ \\
\hline Gastrointestinal & $\begin{array}{c}\text { Constipation } \\
\text { Nausea } \\
\text { Vomiting } \\
\text { Abdominal pain } \\
\text { Heartburn } \\
\text { Dysphagia } \\
\text { Jaundice } \\
\text { Diarrhea } \\
\text { Unspecified/mixed }\end{array}$ & $\begin{array}{l}3(20) \\
2(15) \\
1(7.6) \\
1(7.6) \\
2(15) \\
1(7.6) \\
1(7.6) \\
1(7.6) \\
1(7.6)\end{array}$ \\
\hline Endocrinological & $\begin{array}{c}\text { Polydipsia } \\
\text { Heat intolerance } \\
\text { Cold intolerance } \\
\text { Sweating } \\
\text { Unspecified/mixed }\end{array}$ & $\begin{array}{l}8(54.5) \\
2(13) \\
1(6) \\
2(13) \\
2(13)\end{array}$ \\
\hline Respiratory & $\begin{array}{l}\text { Breathing problem } \\
\text { Cough \& Flu } \\
\text { Hemoptysis } \\
\text { Mixed Symptoms }\end{array}$ & $\begin{array}{c}3(37) \\
2(25) \\
1(12.5) \\
2(25)\end{array}$ \\
\hline Renal & $\begin{array}{l}\text { Increased frequency } \\
\text { Dysuria } \\
\text { Unspecified/mixed }\end{array}$ & $\begin{array}{l}4(50) \\
3(37.5) \\
1(12.5)\end{array}$ \\
\hline Dental & $\begin{array}{c}\text { Xerostomia } \\
\text { Poor oral hygiene }\end{array}$ & $\begin{array}{l}6(85.5) \\
1(14.5)\end{array}$ \\
\hline Dermatological & $\begin{array}{c}\text { Rash } \\
\text { itching }\end{array}$ & $\begin{array}{l}3(60) \\
2(40)\end{array}$ \\
\hline Musculoskeletal & $\begin{array}{c}\text { Joint pain } \\
\text { Unspecified }\end{array}$ & $\begin{array}{l}4(80) \\
1(20)\end{array}$ \\
\hline Genital & Unspecified & $1(100)$ \\
\hline Central nervous system & $\begin{array}{c}\text { Headache } \\
\text { Fits } \\
\text { Blackouts } \\
\text { Dizziness } \\
\text { Unspecified/mixed }\end{array}$ & $\begin{array}{l}5(42) \\
2(16.6) \\
1(8.2) \\
2(16.6) \\
2(16.6)\end{array}$ \\
\hline
\end{tabular}




\section{Discussion}

Other studies pertinent to this subject also found chronic physical health problems as frequent as $74 \%$ among patients with severe mental illness and about half of the individuals had experience of more than two kinds of chronic physical health problems. Chronic pulmonary illness was found to be more prevalent in such problems (Jones et al., 2004). In our study, about one third $(33 \%)$ of the patients were already diagnosed with certain medical comorbidity. While in the undiagnosed physical complains endocrinological, GI, CNS and CVS related complaints were more frequent (Figure 3).

Due to common risk factors (obesity, smoking, dyslipidemia) and antipsychotic use, disorders such as cardiovascular diseases and diabetes mellitus mostly prevails in people with severe mental illness (Schizophrenia, Depression, and Bipolar disorder) (Hert et al., 2009). Our study sample was pronounced with psychotic patients (Schizophrenia 42.4\%, Psychosis NOS 24.7\%) and similarly the antipsychotic use $78.8 \%$ (Figure 2). This is controversial to the available evidence where neurotic problems like depression, anxiety are considered to be more prevalent than psychotic disorders. It may be due to the fact that people with neurotic problems usually hardly seek help from psychiatric facility and therefore psychotic problems seem to be over presented. In our study overall female proportion is lesser i.e. $34 \%$, this might be due to cultural inhibition and less acceptance of psychological problems.

As we broadly compare our study results to previous evidences, (Table 2), constipation has been found a frequent problem (20\%) in psychiatric patients especially of old age (Vessurun et al., 2016). Other gastrointestinal complaints like nausea, anorexia, and flatulence we also found prevalent mostly in neurotic patients and ultimately label to be suffering from irritable bowel syndrome (Sobański et al.,
2015). Palpitation is one of the frequent physical complaint in our patients (Table 2). Studies have identified bidirectional relation of cardiovascular and psychiatric problems, both direct and neurochemical effects (Christoph et al, 2014 \& Shah et al., 2004). It is very important to identify its exact relationship in particular patient because the management plan would vary (Alijaniha et al., 2016). Headache also has a remarkable association with psychiatric problems (Table 2). The evidence supports its both comorbid and associated presentation with Psychiatric disorders, especially migraine headache with that of tension, irritability and anxiety (Shakya, 2015). Frequent drinking of water i.e., polydipsia has an association with Schizophrenia, anxiety and depressive disorders. But it has its medical basis and medical complications (hyponatremia) as well. The reliable and economical physiological tests are available to easily differentiate and manage this condition (Calara et al., 2017).

Breathing problem and impaired lung function have found to be frequent especially in Schizophrenia. Its pathological presentation is almost similar to that of pneumonia, chronic obstructive pulmonary disease and chronic bronchitis while clinically it can be easily missed (Partti et al., 2015). Our patients also had breathing complains (Table 2). Psychiatric disorders like bipolar affective disorder, depressive disorder, and anxiety are identified as risk factor for joint pain disorder like osteoarthritis possibly due to medication side effects and unhealthy lifestyle or obesity (Huang et al., 2016). Urinary complains are also frequent as in our study mental health professionals rarely take it considerable to rule out possible pathologies (Przydacz et al., 2017). Genital problems are usually unreported, unaddressed or misidentified (Basson et al., 2018 \& Grover et al., 2016). In our study, most genital complains were unspecified it might be due to taboo or insufficient 
professional skills (Table 2). Xerostomia is identified as a frequent dental problem study $(85.5 \%)$ possibly due to poor diet and medication side effects (Tomar et al., 2011 $\&$ Kisley et al., 2011).

With such frequent presentation, physical disorders are often missed even by nonmental health professionals. Various direct or indirect factors are responsible such as poor communication and handling skills for challenging behavior of the patient, complex clinical presentation and overburdening (Shefer et al., 2014).To overcome this issue of a significant association between physical and psychiatric problems which worsen quality of life and increases the health care burden, there is a high need to take certain steps. Education and awareness of healthcare professionals are instrumental among all. Beside these improving communication among primary care and specialist health professionals by inclusion of mental health with general medical care (Druss, 2011), involving significant other in the care to emulate and maintain healthy behaviors and habits such as physical activity, proper sleep, avoidance of smoking, alcohol or other substance abuse and intake of healthy diet (Happell 2012 \& Thoits, 2011) and monitoring physical and mental health status and effect of treatment (Carlier, 2012 \& Eldridge, 2011). Although interventional studies evidence is scarce (Hardy et al., 2011) but there are good results of even involving mental health nurses in improving care and services by monitoring physical health (Bradshaw, 2012).

The study has certain limitations, results cannot be generalized due to small sample size and short study duration, the demographic details were insufficient, the association and correlation of variables could not be studied and the medical specialist opinion couldn't seek about those physical complaints. Our study is an initiation towards more specific and extensive work in this subject like assessing a large sample size that includes both urban and rural population for a long duration to study, the sequence of development of various medical and psychiatric disorders, correlation of physical and psychiatric illness, interventional studies regarding awareness of patients about acquiring healthy lifestyle and regular physical checkup in case of presence of risk factors and also education of mental health professionals regarding monitoring, early identification and its impact on clinical outcome as well as for liaison work involving general health professionals regarding approaching patients with psychiatric presentation.

Conclusion

Our study concluded that somatic complaints are frequent in patients with psychiatric illness in almost all systems i.e. CVS, GI, CNS, respiratory, dental, genital, dermatological, endocrine, musculoskeletal and renal. Physical monitoring is crucial for early identification. It is recommended to identify, properly investigate and manage somatic complains in patients with mental illness to improve overall prognosis and quality of life. It can be achieved by improving the skills of health professionals.

\section{Conflicts of Interests}

None.

\section{Acknowledgment}

We would like to acknowledge the patients enrolled in the study and their attendants for cooperation.

\section{Funding}

None.

\section{References}

- Alijaniha, F., Noorbala, A., Afsharypour, S., Naseri, M., Fallahi, F., Mosaddegh, M., Zadeh, S., Sadrai, S. (2016). Relationship between palpitation and mental health. Iran Red Crescent Med J;18(3):e22615

- Alonso, J., Petukhova, M., Vilagut, G., Chatterji, S., Heeringa, S., Üstün, T. 
B, Alhamzawi,

M.C., Angermeyer,

A.O., Viana,

E., Bruffaerts, R., de Girolamo,

G., Florescu, S., Gureje, O., Haro, J.

M., Hinkov, H., Hu, C. Y., Karam, E.

G., Kovess, V., Levinson, D., Medina-

Mora, M. E., Nakamura, Y., Ormel,

J., Posada-Villa, J., Sagar, R., Scott, K.

M., Tsang, A., Williams, D. R., Kessler,

R. C., (2011). Days out of role due to common physical and mental conditions: results from the WHO WMH survey. Mol Psychiatry; 16(12):12341246.

- Basson, R., Gilks, T., (2018). Women sexual disorders associated with psychiatric disorders and their treatment. Sage J:e1177

- Bradshaw, T., (2012). Evolving role of mental health nurses in physical health care of people with serious mental health illness. Int $\mathbf{J}$ Ment Health Nurs; 21(3):266-273.

- Calara, O.S., Bettina, W., Mirjam, C. (2017). Primary polydipsia in the medical and psychiatric patient: Characteristics, complications and therapy. Swiss Med wkly;147:w14514

- Carlier, I. V., Meuldijk, D., Van Vliet, I. M., Van Fenema, E., Van der Wee, N. J., \& Zitman, F. G. (2012). Routine outcome monitoring and feedback on physical or mental health status: evidence and theory. J Eval Clin Pract; 18(1):104-110.

- Christoph, M., Christoph, A., Dannemann, S., Poitz, D., Pfluecke, C., Strasser, R. H., Wunderlich, C., Koellner, V., Ibrahim, K. (2014). Mental symptoms in patients with cardiac symptoms and normal coronary arteries. Open heart;1:e000093

- De Hert, M., Cohen, D., Bobes, J., Cetkovich-Bakmas, M., Leucht, S., Ndetei, D. M., Newcomer, J. W., Uwakwe, R., Asai, I., Möller, H. J., Gautam, S., Detraux, J., Correll, C. U. (2011). Physical illness in patients with severe mental disorders II. Barriers to care, monitoring and treatment guidelines plus recommendations at the system and individual level. World Psychiatry; 10(2):138-151.

- De Hert, M., Dekker, J. M., Wood, D., Kahl, K. G., Holt, R. I. G., \& Möller, H. J. (2009). Cardiovascular disease and Diabetes in people with severe mental illness supported by the position statement from European Psychiatric Association(EPA),

European Association for the Study of Diabetes(EASD) and the European Society of Cardiology(ESC). Eur Psychiatry; 24:412-424.

- De Hert, M., Correll C. U., Bobes J, Cetkovich-Bakmas M., Cohen, D., Asai, I., Detraux, J., Gautam, S., Möller, H. J., Ndetei, D. M., Newcomer, J. W., Uwakwe, R., Leucht, S. (2011). Physical illness in patients with severe mental disorders I. Prevalence, impact of medications and disparities in health care. World Psychiatry; 10(1):52-77.

- Druss, B. G. (2011). Mental disorders and medical comorbidity. Res Synth Rep No.21 Robertwood Johnson Foundation, United states.

- Eldridge, D. (2011). A wellbeing support program for patients with severe mental illness: a service evaluation. BMC Psychiatry 21; 11(1):1.

- Gray, R. (2012). Physical health and mental illness: A silent scandal. Int J Ment Health Nurs; 21(3):191-192.

- Grover, S., Avasthi, A., Gupta, S., Hazari, N., Malhotra, N. (2016).Do female patients with nonpathological vaginal discharge need the same evaluation as for Dhat syndrome in males? Indian J Psychiatry;58(1):61-69

- Hall, R. C., Gardner, E. R., Stickney, SK, LeCann, A. F., Popkin, M. K. (1980). Physical illness manifesting as psychiatric disease II. Analysis of a state hospital inpatient population. Arch Gen Psychiatry; 37(9):989-995. 
- Happell, B. (2012). Health behavior interventions to improve physical health in individuals diagnosed with a mental illness: A systematic Review. Int J Ment Health Nurs; 21(3):236-247.

- Hardy, S., White, J., Deane, K., Gray, R. (2011). Educating health care professionals to act on the physical health needs of people with serious mental illness: a systematic search for evidence. J Psychiatr Ment Health Nurs; 18(8):721-727.

- Hayward, C. (1995). Psychiatric illness and cardiovascular disease risk. Epidemiol Rev; 17(1):129-138.

- Hitchen, L. (2011). Psychiatrists neglect patients with physical health problem, says study. BMJ; 342:d5209.

- Huang, S. W., Wang, W. T., Lin, L. F., Liao, C. D., Liou, T. H., Lin, H. W. (2016). Association between psychiatric disorders and osteoarthritis: a nationwide longitudinal populationbased study. Medicine;95(26):e4016

- Jessurun, J. G., van Harten, P. N., Egberts, T. C., Pijl, Y. J., Wilting, I., \& Tenback, D. E. (2016). The relation between psychiatric diagnoses and constipation in hospitalized patients: A Cross-sectional study. Psychiatry J;e2459693.

- Jones, D. R., Macias, C., Barreira, P. J., Fisher, W. H., Hargreaves, W. A., Harding, C. M. (2004). Prevalence, severity and co-occurrence of chronic physical health problems of persons with severe mental illness. Psychiatr Serv; 55(11):1250-1257.

- Kisely, S., Quek, L. H., Pais, J., Lalloo, R., Johnson, N. W., \& Lawrence, D. (2011). Advanced dental disease in people with severe mental illness: systematic review and metanalysis. Br J Psychiatry; 199(3):187-193.

- Koranyi, E. K. (1979) Morbidity and rate of undiagnosed physical illnesses in a psychiatric clinic population. Arch Gen Psychiatry; 36(4):414-419.
- Larsen, B. A., \& Christenfeld, N. J. (2009). Cardiovascular disease and psychiatric comorbidity: The potential role of perseverative cognition. Cardiovascular Psychiatry Neurol; 791017:8 pages.

- Lawrence, D., Hancock, K. J., \& Kisely, S. (2013). The gap in life expectancy from preventable physical illness in psychiatric patients in Western Australia: retrospective analysis of population based registers. Bmj, 346, f2539.

- Leboyer, M., Soreca, I., Scott, J., Frye, M., Henry, C., Tamouza, R., \& Kupfer, D. J. (2012). Can Bipolar disorder be viewed as a multisystem inflammatory disease? J Affect Disord; 141(1):1-10.

- Mercer, S. W., Gunn, J., Bower, P., Wyke, S., \& Guthrie, B. (2012). Managing patients with mental and physical multimorbidity. BMJ 3; 345:e5559.

- Nousen, E. K., Franco, J. G., \& Sullivan, E. L. (2013). Unveiling the mechanisms responsible for the comorbidity between metabolic syndrome and mental health disorders. Neuroendocrinol J.; 98(4):254-266.

- Partti, K., Vasankari, T., Kanervisto, M., Perälä, J., Saarni, S. I., Jousilahti, P., Lönnqvist, J., Suvisaari, J. (2015). Lung function and respiratory diseases in people with psychosis: population-based study. Br. J Psychiatry;207(1):37-45

- Phillips, K., \& Clauw, D. J. (2011). Central pain mechanisms in chronic pain states- may be its all in their head. Best Pract Res Clin Rheumatol; 25(2):141154.

- Przydacz, M., Golabek, T., Sobanski, J., Jaworska, K., Skalski, M., Swierkosz, A., Dudek, P., Sobieraj, D., Dudek, D., Chłosta, P. (2017).Perception of lower urinary tract symptoms in mentally affected patients.Psychiatr Pol;51(5):963-978

- Scott, D., \& Happell, B. (2011). The high prevalence of poor physical health 
and unhealthy life style behaviours in individuals with severe mental illness. Issues Ment Health Nurs 19; 32(9):589597.

- Scott, K. M., Von Korff, M., Alonso, J., Angermeyer, M. C., Bromet, E., Fayyad, J., de Girolamo, G., Demyttenaere, K., Gasquet, I., Gureje, O., Haro, J. M., He, Y., Kessler, R. C., Levinson, D., Medina M. M. E., Oakley, B. M., Ormel, J., Posada-Villa, J., Watanabe, M., Williams, D. (2009). Mental-physical co-morbidity and its relationship with disability: results from the World Mental Health Surveys. Psychol Med.; 39(1):33-43.

- Shah, S. U., White, A., White, S., \& Littler, W. A. (2004). Heart and mind: (1) relationship between cardiovascular and psychiatric conditions. Postgrad Med J.; 80:683-689.

- Shakya, D. R. (2015). Psychopathology and Psychiatric disorders in psychiatric outpatients with migraine headaches. Neuropsychiatry; 5(1):30-36.

- Shefer, G., Henderson, C., Howard, L. M., Murray, J., \& Thornicroft, G. (2014). Diagnostic Overshadowing and Other Challenges Involved in the Diagnostic Process of Patients with Mental Illness Who Present in Emergency Departments with Physical Symptoms - A Qualitative Study. PLoS One; 9(11):e111682.

- Smith, P. J., \& Blumenthal, J. A. (2011). Psychiatric and behavioural aspects of cardiovascular disease: epidemiology, mechanisms and treatments. Rev Esp Cardiol; 64(10):924-933.

- Sobański, J. A., Klasa, K., Mielimąka, M., Rutkowski, K., Dembińska, E., Müldner-Nieckowski, Ł., Popiołek, L. (2015). The crossroads of gastroenterology and psychiatry - what benefits can psychiatry provide for the treatment of patients suffering from gastrointestinal symptoms. Przegląd Gastroenterologiczny, 10(4),222-228

- Taylor, V. H., McIntyre, R. S., Remington, G., Levitan, R. D.,
Stonehocker, B., \& Sharma, A. M. (2012). Beyond pharmacotherapy: understand links between obesity and chronic mental illness. Can J Psychiatry; 57(1):5-12.

- Thoits, P. A. (2011). Mechanism linking social ties and support to physical and mental health. J Health Soc Behav; 52(2):145-161

- Thornicroft, G. (2011). Physical health disparities and mental illness: the scandal of premature mortality. $\mathrm{Br} \mathrm{J}$ Psychiatry; 199(6):441-442.

- Tomar, B., Bhatia, N. K., Kumar, P., Bhatia, M. S., \& Shah, R. J. (2011). The Psychiatric and dental interrelationship. Delhi Psychiatry J; 14(1): 138-142. 